\title{
Mínima intervenção (MI) no tratamento da cárie profunda em dentística
}

\author{
Minimal intervention (MI) in the treatment of deep caries in dentistry
}

Intervención mínima (IM) en el tratamiento de la caries profunda en odontología

Clécio Tenório de Azevedo ${ }^{1}$, Karla Hevilly Mendes de Andrade Ferreira ${ }^{1}$, Izabel Cristina Gomes de Mendonça ${ }^{1 *}$.

\section{RESUMO}

Objetivo: Investigar, na literatura pertinente e baseada em evidências, os princípios da mínima intervenção e demonstrar em quais casos eles podem ser empregados na dentística. Revisão Bibliográfica: A filosofia da Mínima Intervenção (MI) no manejo da cárie não é uma novidade, há anos pesquisadores renomados demonstram que é possível prevenir e tratar a cárie dental com o domínio do conhecimento da sua etiologia e dos mecanismos de evolução. As condutas minimamente invasivas são vistas, até então, com suspeita pela grande maioria dos profissionais da Odontologia que, imbuídos dos melhores propósitos, ainda tratam as sequelas da cárie da forma tradicional, menos conservadora e propensa a procedimentos cada vez mais complexos. É difícil mudar dogmas que foram incorporados por décadas, visto que os conceitos da Odontologia predominantemente curativa, embora evidências mostrem o contrário, permanece sendo ensinadas nas universidades. Considerações Finais: Os estudos citados neste trabalho sustentam que é possível a manutenção de tecido cariado, em cáries profundas na dentição permanente, em casos onde a remoção completa do mesmo possa expor a polpa, comprometendo a vitalidade do dente.

Palavras-chave: Dentística operatória, Tratamento conservador, Cárie dentária, Dentina, Capeamento pulpar.

\section{ABSTRACT}

Objective: To investigate, in the pertinent and evidence-based literature, the principles of minimum intervention and demonstrate in which cases they can be used in dentistry. Bibliographic Review: The philosophy of Minimum Intervention (MI) in the management of caries is not new, for years renowned researchers have demonstrated that it is possible to prevent and treat dental caries with the knowledge of its etiology and the mechanisms of evolution. Minimally invasive conducts are viewed, until then, with suspicion by the vast majority of dentistry professionals who, imbued with the best purposes, still treat the caries sequelae in the traditional way, less conservative and prone to increasingly complex procedures. It is difficult to change dogmas that have been incorporated for decades, since the concepts of predominantly curative dentistry, although evidence shows the opposite, remains being taught in universities. Final Considerations: The studies cited in this work maintain that it is possible to maintain decayed tissue, in deep cavities in the permanent dentition, in cases where complete removal of it may expose the pulp, compromising the vitality of the tooth.

Keywords: Operative dentistry, Conservative treatment, Dental caries, Dentin, Pulp capping.

RESUMEN

Objetivo: Investigar, en la literatura pertinente y basada en evidencias, los principios de mínima intervención y demostrar en qué casos pueden ser utilizados en odontología. Revisión Bibliográfica: La filosofía de Mínima Intervención (MI) en el manejo de la caries no es nueva, durante años reconocidos investigadores han demostrado que es posible prevenir y tratar la caries dental con el conocimiento de su etiología y los mecanismos de evolución. Las conductas mínimamente invasivas son vistas, hasta entonces, con recelo por

${ }^{1}$ Centro Universitário Cesmac (CESMAC), Maceió - AL. ${ }^{*}$ E-mail: belgomess@gmail.com 
la gran mayoría de los profesionales de la odontología que, imbuidos de las mejores finalidades, aún tratan las secuelas de caries de la forma tradicional, menos conservadora y propensa a procedimientos cada vez más complejos. Es difícil cambiar los dogmas que se vienen incorporando desde hace décadas, ya que los conceptos de odontología predominantemente curativa, aunque la evidencia muestra lo contrario, sigue siendo enseñado en las universidades. Consideraciones Finales: Los estudios citados en este trabajo sostienen que es posible mantener el tejido cariado, en cavidades profundas de la dentición permanente, en los casos en que la remoción completa del mismo pueda exponer la pulpa, comprometiendo la vitalidad del diente.

Palabras clave: Odontología operatoria, Tratamiento conservador, Caries dental, Dentina, Recubrimiento pulpar.

\section{INTRODUÇÃO}

Mudanças de paradigmas sempre são vistas com ressalvas e precisam ser incessantemente provadas até que sejam aceitas e adotadas na clínica diária. A filosofia da Mínima Intervenção (MI) no manejo da cárie não é uma novidade, há anos pesquisadores renomados vêm demonstrando que é possível prevenir e tratar a cárie dental com o domínio do conhecimento da sua etiologia e seus mecanismos de evolução em consonância com o emprego de materiais adesivos que contenham flúor na sua composição (INNES NPT, et al., 2019).

A Ml está respaldada em abordagens conservadoras e preventivas que paralisam a evolução da doença e/ou impedem seu surgimento ao mesmo tempo em que promove a mínima remoção de tecido dental em abordagens nas fases mais evoluídas da doença, tratando as sequelas da cárie sem inviabilizar a vitalidade do dente (FRENCKEN JE, et al., 2012).

A cárie dental é uma condição patológica resultante da atividade bacteriana no biofilme que acomete os constituintes minerais dos dentes, afetando indivíduos de todas as faixa-etárias, classes socioeconômicas, culturas e etnias (FEJERSKOV O, et al., 2015).

Essa doença caracteriza-se pela dissolução dos tecidos dentários por meio de ácidos oriundos da fermentação de carboidratos, em particular a sacarose, por bactérias cariogênicas. A prevenção de seu desenvolvimento e controle se dá pelo comedimento do biofilme, mudança nos hábitos de higiene bucal e controle da dieta, no tocante ao consumo de sacarose (SILVA BP, et al., 2018).

O tratamento tradicional das lesões cariosas, caracterizado pela remoção de toda dentina que foi comprometida, a fim de eliminar a atividade cariogênica e deixar uma base de tecido hígido e endurecido para a restauração, foi durante muito tempo a terapêutica predominante (RIBEIRO AA, 2016).

Contudo, esse tratamento provoca diversas vezes perda de tecido dental sadio, fragilizando a estrutura remanescente, aumentando as chances de fratura e diminuindo a longevidade das restaurações, levando ao que se estabeleceu chamar de ciclo restaurador repetitivo, caracterizado pela constante substituição das restaurações por procedimentos cada vez mais complexos culminando com a perda do elemento dental (BATISTA MJ, et al., 2015)

Ao longo dos anos, as pesquisas científicas sobre a cárie dentária possibilitaram uma maior compreensão tanto da etiologia quanto da evolução da doença nos tecidos dentários, fato que, aliado à evolução dos materiais adesivos, contribuiu de forma decisiva para uma mudança significativa no tratamento das lesões cariosas (TUMENAS I, et al, 2014; KUTSCH VK, 2014; PHILIP N, et al., 2018)

Essa nova filosofia de tratamento passou a priorizar abordagens mais conservadoras e menos invasivas, culminando com o advento da mínima intervenção na Odontologia, a qual envolve técnicas de promoção de saúde e prevenção, para impedir a instalação da lesão, e a adoção de condutas clínicas na paralização do processo carioso e controle da evolução em lesões incipientes. 
Enquanto que, nos estágios mais avançados, onde há envolvimento dentinário, a filosofia de mínima intervenção preconiza o selamento de fossas e fissuras com o intuito de suprimir a entrada de substrato e paralisar o desenvolvimento da lesão, tornando o tratamento restaurador menos agressivo e preservando ao máximo estruturas dentárias ainda hígidas e a vitalidade pulpar (TUMENAS I, et al., 2014; FEJERSKOV O, et al., 2015).

As condutas minimamente invasivas ainda são vistas com suspeita pela grande maioria dos profissionais da Odontologia que, imbuídos dos melhores propósitos, ainda tratam as sequelas da cárie da forma tradicional, menos conservadora e propensa a procedimentos cada vez mais complexos.

Diante do exposto, este artigo tem por objetivo investigar, na literatura pertinente e baseada em evidências, os princípios da mínima intervenção empregados na Dentística em prol da manutenção da integridade e da vitalidade de dentes que foram comprometidos por lesões cariosas extensas.

\section{REVISÃO BIBLIOGRÁFICA}

\section{Tratamento da cárie profunda}

No tocante à mínima intervenção, um ponto sensível e que gera muita discussão diz respeito à remoção de dentina cariada. A lesão na dentina tem início quando a cavidade ultrapassa a junção amelodentinária e alcança uma profundidade que, além de reter o biofilme, dificulta a sua remoção pela escovação. Quando isto acontece, a dentina sofre uma desmineralização superficial que vai aprofundando à medida que o desafio ácido se prolonga e poderá alcançar o órgão pulpar (BRAGA MM, et al., 2010).

A dentina é uma matriz orgânica calcificada, altamente organizada que consiste em cristais de hidroxiapatita e de uma rede colágena e proteica sintetizada e secretada por odontoblastos da polpa, com grande capacidade de responder a estímulos externos. Quando as bactérias cariogênicas invadem a dentina, uma grande resistência à progressão da lesão cariosa é montada pelos tecidos dentino-pulpares. As moléculas de sinalização e os fatores de crescimento liberados na desmineralização da dentina regulam positivamente a atividade dos odontoblasto e atuam como células sensoras.

Após a estimulação cariosa, os odontoblastos iniciam uma reação inflamatória pela produção de quimiocinas e sintetizam uma dentina terciária protetora, atubular, que efetivamente impede a migração de bactérias ao longo dos túbulos dentinários, protegendo assim a polpa dentária da invasão (CONRADS G e ABOUT I, 2018). Quando a polpa assume papel reparador, a camada de odontoblastos mantém sua deposição de matriz, com os túbulos organizados e paralelos (ARAÚJO NC, et al., 2010).

Em uma lesão de cárie ativa são encontradas, na dentina, duas zonas distintas do ponto de vista morfológico, bioquímico, bacteriológico e fisiológico. A mais externa (infectada) tem intensa atividade bacteriana, material necrótico, se apresenta irreversivelmente desnaturada, não passível de remineralização e que deve ser removida durante o procedimento restaurador.

E uma camada mais profunda que se mostra reversivelmente desnaturada e passível de remineralização, devendo ser preservada. Nesse local, a atividade cariosa é menor e a presença bacteriana é muito pequena, e a desorganização da dentina é decorrente da ação dos ácidos acumulados na primeira camada, recebendo o nome de dentina contaminada ou afetada. A cárie ativa de progressão rápida é caracterizada pela ausência de reação de defesa por parte dos tecidos dentários o que leva a um aumento na permeabilidade da dentina, provocando dor (ARAÚJO NC, et al., 2010).

Caso a progressão da cárie não seja impedida e as bactérias penetrem na polpa promovendo a destruição da camada de odontoblastos subsequente, a polpa ainda se defende sintetizando dentina terciária graças à presença de células ectomesenquimais, remanescentes da odontogênese, que se diferenciam em odontoblastos.

O órgão pulpar tem também uma regulação local bem desenvolvida da sua inflamação, regeneração e vascularização creditada à atividade de diferentes tipos de células, principalmente os fibroblastos (CONRADS G e ABOUT I, 2018). A Figura 1 abaixo representa o mecanismo de defesa dos tecidos dentino-pulpares à invasão bacteriana. 
Figura 1 - Mecanismo de defesa dos tecidos dentino-pulpares à invasão bacteriana.

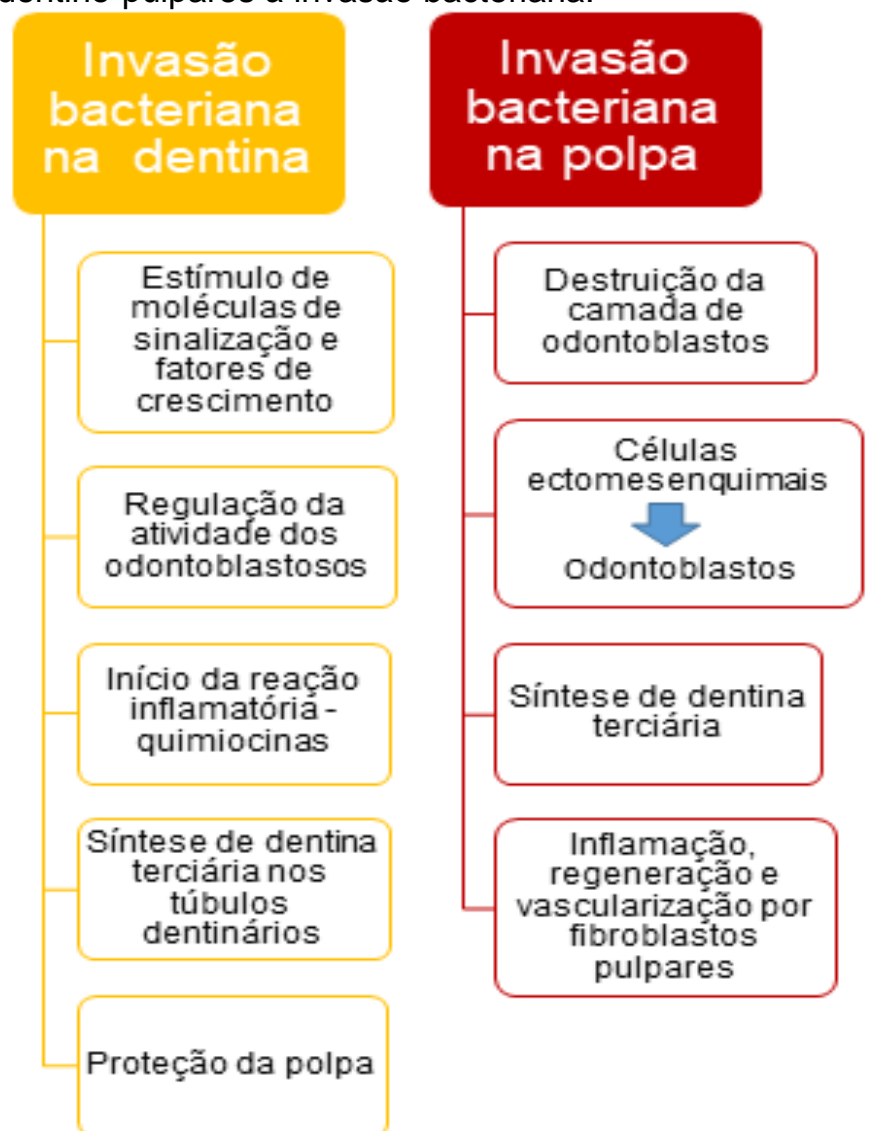

Fonte: Azevedo CT, et al., 2020.

Ao longo dos anos, propagou-se que o tratamento restaurador deveria limitar-se à remoção completa da lesão cariosa com o intuito de eliminar totalmente a doença, entretanto, esse método pode comprometer a vitalidade do dente em lesões profundas. Segundo Maltz M, et al. (2011), a remoção da dentina cariada é ponto de discórdia no meio científico há anos, devido principalmente à dificuldade de distinção clínica entre dentina infectada e sadia, tendo em vista os critérios de cor e dureza preconizados como sinal de dentina saudável, estão sendo questionados por diversos pesquisadores que constataram a presença de bactérias na dentina após a completa remoção do tecido cariado.

Além do mais, a invasão da dentina por microrganismos precede a ocorrência de alterações destrutivas e amolecimento deste tecido, por isso, mesmo parecendo dura à compressão com um instrumento manual, a dentina remanescente ainda pode apresentar túbulos infectados. Dessa forma, os avanços dos estudos no que se referem à origem da doença, sua evolução e o comportamento dos tecidos a ela, além das técnicas preventivas e o aprimoramento de materiais restauradores, possibilitaram o surgimento de métodos menos invasivos no seu tratamento (FARGES JC, et al., 2015; ARAÚJO NC, et al., 2010; OZ FD, et al., 2010).

Carvalho JC, et al. (2016), discutem em uma extensa revisão da literatura, três opções de tratamento de lesões de cárie profunda em dentes permanentes, com resposta positiva a testes de vitalidade pulpar. A primeira delas, denominada remoção seletiva para dentina firme ou tratamento convencional, preconiza a remoção total da cárie até atingir dentina firme, abordagem com grande possibilidade de exposição pulpar, com taxa de sobrevida de $30 \%$ após 1 a 3 anos de acompanhamento e $13 \%$ após 10 anos. A outra técnica denominada escavação passo a passo, também conhecida como stepwise ou tratamento expectante, sugere a manutenção da dentina afetada, a qual é totalmente removida após um período de observação, em um processo de duas ou mais etapas, mostrou uma taxa de sobrevivência de $74 \%$ após um ano de acompanhamento (BJØRNDAL L, et al., 2010; ARAÚJO NC, et al., 2010; OZ FD, et al., 2010). 
A terceira e mais polêmica, denominada remoção seletiva da dentina amolecida, preconiza a permanência de cárie na parede de fundo e remoção total da mesma nas paredes circundantes de forma definitiva, ou seja, sem uma sessão para a remoção da dentina cariada. A taxa de sobrevivência dessa terapia foi de $90 \%$ após três anos, 82\% após cinco anos e 63\% em 10 anos de acompanhamento (MALTZ M, et al., 2011).

Pesquisas têm demonstrado que a dentina infectada em lesões cavitadas não precisa ser removida para deter a sua progressão, pois está comprovado que o selamento desta dentina na cavidade, por uma restauração bem selada, irá inviabilizar os microrganismos remanescentes pela falta do substrato que as mantêm vivas. Da mesma forma que a eliminação completa do biofilme diante da limpeza protagonizada pelo paciente, quando a lesão permite e está acessível e sem retenções, irá paralisar a doença (FEJERSKOV O, et al., 2015; OZ FD, et al., 2010).

Entre as técnicas de mínima intervenção citadas acima, o tratamento expectante é o mais aceito pelos dentistas. Nele a remoção da dentina cariada, em um processo de duas ou mais etapas, tem por finalidade evitar exposição pulpar e permitir as reações fisiológicas de defesa tanto da dentina como da polpa (ARAÚJO NC, et al., 2010; OZ FD, et al., 2010).

Na primeira sessão do Tratamento Expectante, realiza-se a remoção da dentina mais externa, superficial, que está infectada e desorganizada, seguida do selamento temporário da cavidade por 45 a 60 dias, podendo ser estendido até seis meses. Esse período de espera tem por finalidade parar a agressão, impedindo a entrada de substrato com consequente redução de microrganismos, como também permitir uma reposta do dente aos estímulos sofridos.

Na segunda sessão, todo o tecido cariado remanescente é removido e nota-se que a dentina subjacente adquire uma coloração e consistência parecidas às lesões que estão inativas, o que denota a remineralização da lesão. Ao final do processo a cárie é removida, a vitalidade do dente preservada e os resultados terapêuticos, satisfatórios e favoráveis (BJØRNDAL L, et al., 2019; OZ FD, et al., 2010; BJØRNDAL L, et al., 2010).

Contudo, evidências apontam que, dentre as abordagens modernas de gerenciamento de cárie, a remoção seletiva da dentina amolecida (com selamento definitivo de tecido cariado) (Figuras 2 A e B) é a técnica recomendada em lesões cariosas profundas, apresentando as maiores taxas de sucesso. Enquanto a remoção total do tecido cariado tem uma menor taxa de sucesso devido ao aumento do risco da exposição pulpar na presença de dentina infectada. E no tratamento expectante existe uma grande possibilidade de exposição na segunda etapa, quando a dentina cariada é totalmente removida (CARVALHO JC, et al., 2016).

Infelizmente a prevalência de perdas dentárias no Brasil é considerada alta, os achados de um estudo epidemiológico nacional de saúde bucal, realizado em 2002/2003 por Barato e Peres (2009) com 16.833 participantes de ambos os sexos dos 15 aos 19 anos, mostraram que 16.178 dentes foram extraídos dos quais $92,71 \%$ foram em decorrência de cárie. Os primeiros molares contribuíram com mais de $55 \%$ do total dos dentes perdidos e, dentre estes, as perdas dos inferiores ( 36 e 46 ) representaram aproximadamente $41 \%$.

Esses dados foram confirmados por Normando D e Cavacami $C$ (2010), segundo os pesquisadores os índices de perdas dentárias no Brasil são alarmantes, principalmente na população de baixa renda, sendo o primeiro molar inferior permanente o elemento mais extraído. De acordo com os autores, a perda bilateral do primeiro molar inferior permanente é capaz de interferir na direção do crescimento facial, levando a um giro anti-horário do plano oclusal, e uma suave diminuição na altura facial inferior e no padrão dentário da arcada inferior, resultando em uma acentuada inclinação para lingual e uma suave retrusão dos incisivos inferiores.

Em um estudo promovido com a intenção de saber a preferência dos profissionais odontológicos a respeito dos procedimentos de remoção cariosa Oz FD, et al. (2010) descobriram que a maior parte deles optam pela remoção completa da cárie, ainda que haja risco de exposição pulpar, logo, é necessário a popularização de técnicas minimamente invasivas entre os profissionais, tendo em vista a saúde do dente e o bem-estar do paciente, pois o principal objetivo clínico é conter as lesões ativas antes de ir para o manejo definitivo dos materiais restauradores. 
A International Caries Consensus Collaboration (ICCC), grupo de 21 especialistas em cariologia de 12 países, inclusive dois brasileiros, sentindo a necessidade de acompanhar as novas diretrizes na abordagem das lesões cariosas, sugeridas por evidências incontestáveis levantadas pela comunidade científica, se reuniu em 2015 para formular um processo de consenso que, entre outras resoluções, determinou como prioridade a "preservação do tecido saudável e remineralizável", obtendo um selamento restaurador adequado, mantendo a saúde pulpar e maximizando o sucesso da restauração.

Os especialistas concordaram que os tecidos contaminados com bactérias ou desmineralizados próximos à polpa não precisariam ser removidos em prol da vitalidade pulpar. E, ao final, sugeriram a técnica de remoção seletiva para dentina amolecida em lesões profundas tanto na dentição decídua como na permanente, sem, no entanto, descartar a remoção gradual (tratamento expectante) como opção de tratamento em dentes permanentes (SCHWENDICKE F, et al., 2016).

Figura 2 - Resposta ao tratamento com remoção seletiva da dentina amolecida, em dente permanente jovem, após 10 meses de monitoramento.
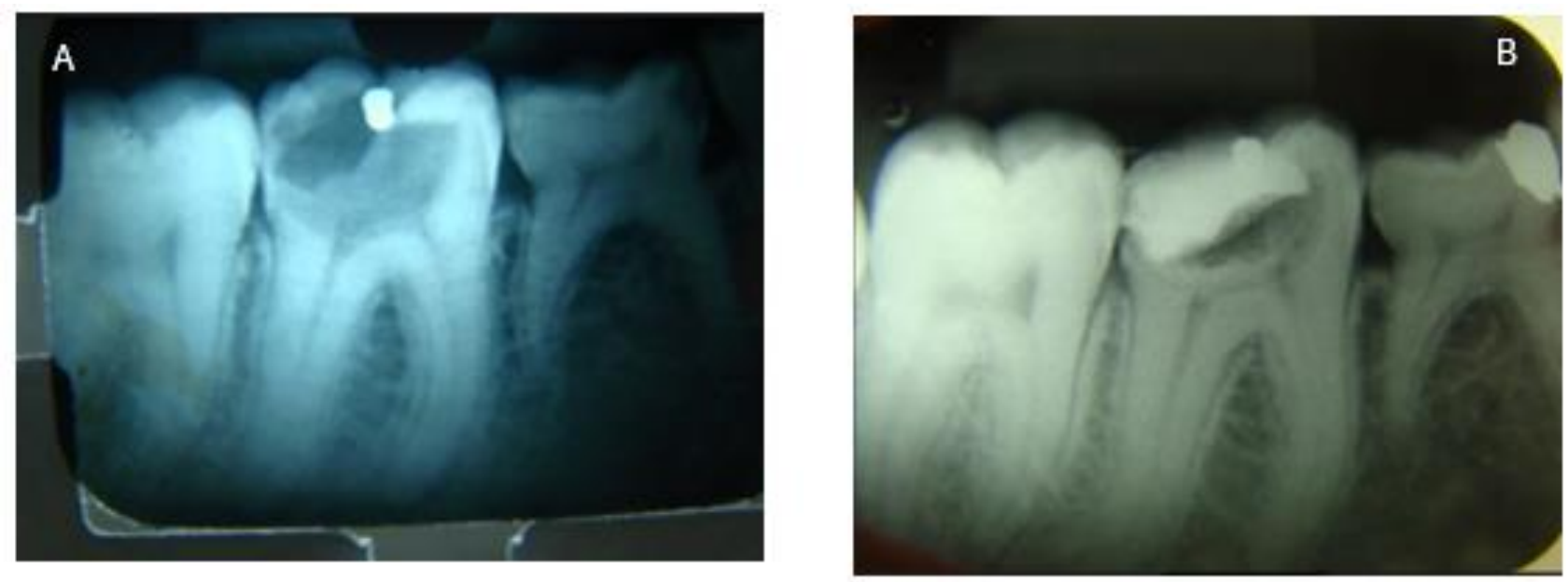

Legenda: Figura A: Radiografia inicial. Figura B: Radiografia após 10 meses, mostrando a camada de dentina terciária sobre a polpa.

Fonte: Azevedo CT, et al., 2020.

\section{Selamento da cavidade após a remoção seletiva da dentina amolecida}

O sucesso do tratamento de lesões profundas nas quais foram feitas remoções seletivas da dentina amolecida está intrinsecamente ligado a um bom selamento da mesma. Portanto, a escolha do material restaurador é um passo muito importante nesse processo e os mais comumente usados são o cimento de ionômero de vidro (CIV) e as resinas compostas. Porém, como uma camada de cárie residual é deixada na cavidade, o material restaurador ideal, além de proporcionar um bom selamento, deveria possuir também um efeito antimicrobiano sobre as bactérias seladas (VILLAT C, et al., 2016; SCHMIDT J, et al., 2020).

Nesse sentido, alguns estudos estão avaliando o efeito anticárie de materiais incorporados com agentes antimicrobianos. O glutaraldeído foi um dos primeiros a ser testado por possuir grande capacidade desinfetante, mas foi deixado de lado porque interferia nas propriedades mecânicas dos adesivos, em seguida os testes com a clorexidina foram iniciados.

Com o passar do tempo e tendo a evolução tecnológica como aliada, os pesquisadores começaram as buscas por outros agentes antimicrobianos (bioativos) que não interferissem nas propriedades do material ao qual seriam incorporados e fossem biocompatíveis. Assim chegaram ao brometo de metacriloiloxidodecilpiridínio (MDPB), ao dimetil metacrilato de cloreto de amônia (DMAE-CB) e mais recentemente ao metacrilato de zinco e até mesmo à própolis (VILLAT C, et al., 2016; MARTINS DO, et al., 2014). 
A solução de clorexidina é compatível com os tecidos dentários e espécies de Streptococcus mutans e Streptococcus sobrinos são sensíveis a ela que também mimetiza a ação dos inibidores biológicos das enzimas metaloproteinases endógenas (MMP), presentes na matriz extracelular da dentina humana, e que possuem intensa atividade metabólica na degradação do colágeno dentinário.

Tanto o MDPP como o DMAE-CB são monômeros compostos da combinação de um grupo metacrilato com uma amônia quartenária, responsável pela ação antimicrobiana de largo espectro, inibem a MMP e quando incorporados aos adesivos resinosos, não interferem nas propriedades dos mesmos além de aumentar a hidrofilia do produto, melhorando a estabilidade dente/restauração, porém, enquanto o MDPB é biocompatível, a segurança biológica do DMAE-CB precisa ainda de comprovação (MARTINS DO, et al., 2014).

Um estudo com o objetivo de comparar as propriedades físico-mecânicas, efeitos antibacterianos e citotoxicidade de cinco resinas compostas, comprovou o efeito antibacteriano das resinas Fill Magic e Bioplic contra $S$. mutans, enquanto Luxatemp mostrou inibição in vitro do acúmulo de biofilme de $S$. mutans e crescimento de $E$. faecalis. Em relação ao teste de viabilidade celular, a Luxatemp foi a mais citotóxica e a Fill Magic, a de menor citotoxidade (PERALTA SL, et al., 2018).

Yadiki JV, et al. (2016) compararam as propriedades antimicrobianas de dois cimentos de ionômero de vidro, com e sem gluconato de clorexidina, em cepas de Streptococcus mutans. Os resultados do estudo confirmaram que a adição de gluconato de clorexidina $5 \%$ aos cimentos de ionômero de vidro Fuji II e Fuji IX resultou em um material restaurador que apresentou propriedades antimicrobianas aumentadas em relação aos cimentos de ionômero de vidro convencionais isolados para aquelas bactérias.

Em uma pesquisa publicada recentemente, os resultados apontaram que um cimento de silicato tricálcico Biodentine ${ }^{\mathrm{TM}}$ (Septodont, Paris), usado para cobrir dentina amolecida residual, pode ter efeito antibacteriano, oferecendo uma opção de tratamento alternativa e segura (SCHMIDT J, et al., 2020).

Diante do que foi descrito até então, é possível perceber que uma geração de materiais bioativos está sendo testada, mas a maior parte das pesquisas sobre eles são in vitro, estudos in vivo ainda são necessários para determinar se eles induzem algum tipo de resistência nas bactérias como também o comportamento clínico dos mesmos. A expectativa de todos é que seus benefícios sejam enormes e prestem um grande serviço à Odontologia minimamente invasiva (CHENG L, et al., 2017).

\section{CONSIDERAÇÕES FINAIS}

Frente ao que foi exposto com base na literatura consultada e cingidos unicamente ao âmbito da ciência, é possível constatar que há evidências contundentes de que a remoção de todos os vestígios de dentina cariada das lesões que se aproximam da polpa não é necessária para o controle da cárie e que os microorganismos remanescentes tornam-se inviáveis devido à perturbação do biofilme e ao isolamento da cavidade por um material restaurador. A International Caries Consensus Collaboration (ICCC) recomenda a manutenção de tecido cariado, na dentição permanente, em casos onde a remoção completa do mesmo possa expor a polpa, comprometendo a vitalidade do dente. Mudanças de paradigma levantam novas questões de pesquisa que precisam ser abordadas, como por exemplo, o desenvolvimento de materiais bioativos, para tornar a prevenção e o tratamento conservador da cárie uma realidade no dia-a-dia dos consultórios com a adoção de medidas minimamente invasivas no tratamento da cárie profunda em Dentística.

\section{REFERÊNCIAS}

1. ARAUJO NC, et al. Considerações sobre a remoção parcial do tecido cariado. IJD, Int. J. dent. [online], 2010; 9(4): 202-209.

2. BATISTA MJ, et al. Classificação das perdas dentárias: fatores associados a uma nova medida em uma população de adultos. Ciênc. Saúde Coletiva [online], 2015; 20(9): 2825-2835.

3. BJØRNDAL L et al. Treatment of deep caries lesions in adults: randomized clinical trials comparing stepwise vs. direct complete excavation, and direct pulp capping vs. partial pulpotomy. Eur J Oral Sci. 2010 Jun;118(3):290-7. 
4. BJØRNDAL L, et al. Treatment of deep caries lesions in adults: randomized clinical trials comparing stepwise vs. direct complete excavation, and direct pulp capping vs. partial pulpotomy. Eur J Oral Sci, 2010; 118: $290-297$.

5. BJØRNDAL L, et al. Management of deep caries and the exposed pulp. International Endodontic Journal, 2019; 949 973.

6. BRAGA MM, et al. Lesões de cárie em dentina: aspectos importantes sobre sua fisiopatologia e progressão. In: IMPARATO JCP. Selamento de cárie: uma alternativa para tratamento de lesões de cárie em dentina. São Paulo. Ed. Santos, 2010. p.13-19.

7. CARVALHO JC, et al. Occlusal Caries: Biological Approach for Its Diagnosis and Management. Caries Res, 2016; 50(6): 527-542.

8. CHENG L, et al. Developing a New Generation of Antimicrobial and Bioactive Dental Resins. J Dent Res, 2017 Jul; 96(8): 855-863.

9. CONRADS G, ABOUT I. Pathophysiology of Dental Caries. Monogr Oral Sci. 2018; 27:1-10.

10. FARGES JC, et al. Dental Pulp Defence and Repair Mechanisms in Dental Caries. Mediators Inflamm. 2015;2015:230251.

11. FEJERSKOV O, KIDD E. Cárie Dentária: a doença e seu tratamento clínico. 2ª ed. São Paulo: Santos, 2011.

12. FEJERSKOV O, et al. Dental Caries: The Disease and Its Clinical Management. 3rd Ed. Oxford (UK): Wiley Blackwell, 2015.

13. FRENCKEN JE, et al. Minimal intervention dentistry for managing dental caries - a review: report of an FDI task group. Int Dent J, 2012 Oct; 62(5): 223-43.

14. INNES NPT, et al. A Century of Change towards Prevention and Minimal Intervention in Cariology. J Dent Res, 2019 Jun; 98(6): 611-617.

15. MALTZ M, et al. Incomplete caries removal in deep lesions: a 10-year prospective study. Am J Dent, 2011; 24: 211 214.

16. MARTINS DO, et al. Agentes antimicrobianos nos sistemas adesivos. Rev. Bras. Odontol. Rio de Janeiro, 2014; 71(2).

17. NORMANDO D, CAVACAMI C. A influência da perda bilateral do primeiro molar inferior permanente na morfologia dentofacial - um estudo cefalométrico. Dental Press J. Orthod. Maringá, 2010 nov/dec; 15(6).

18. OZ FD, et al. Long-term survival of different deep dentin caries treatments: A 5-year clinical study. Niger J Clin Pract, 2019; 22:117-24.

19. PERALTA SL, et al. Evaluation of physical-mechanical properties, antibacterial effect, and cytotoxicity of temporary restorative materials. J Appl Oral Sci, 2018;

20. RIBEIRO AA. Biological Features of Dental Caries. JSM Dent, 2016; (3): 1065-70.

21. SCHMIDT J, et al. Effect of a bioactive cement on the microbial community in carious dentin after selective caries removal - An in-vivo study. J Dent, 2020 Jan; 92:103264.

22. SCHWENDICKE F, et al. Managing carious lesions: consensus recommendations on carious tissue removal. Adv Dent Res, 2016; 28(2): 58-67.

23. SILVA BP, et al. Current trends in the conservative treatment of deep-caries lesion with risk of pulp exposure. Revista Brasileira de Odontologia, 2018; 75:1.

24. TUMENAS I, et al. Odontologia Minimamente Invasiva. Rev. Assoc. Paul. Cir. Dent. São Paulo, 2014; 68(4).

25. VILLAT C, et al. One-step partial or complete caries removal and bonding with antibacterial or traditional self-etch adhesives: study protocol for a randomized controlled trial. Trials, 2016 Aug 15; 17(1): 404.

26. YADIKI JV, et al. Comparative Evaluation of the Antimicrobial Properties of Glass lonomer Cements with and without Chlorhexidine Gluconate. Int J Clin Pediatr Dent, 2016 Apr-Jun; 9(2): 99-103. 